\title{
Face and construct validity of a novel mechanical ERCP simulator
}

\section{(ㄷ)(1) $\odot$}

Authors

Sophia E. van der Wiel, Arjun D. Koch, Marco J. Bruno

Institution

Department of Gastroenterology and Hepatology, Erasmus MC University Medical Center Rotterdam, The Netherlands

submitted 29.8.2017

accepted after revision 27.11.2017

Bibliography

DOI https://doi.org/10.1055/s-0044-101754 |

Endoscopy International Open 2018; 06: E758-E765

(c) Georg Thieme Verlag KG Stuttgart · New York

ISSN 2364-3722

Corresponding author

Sophia E. van der Wiel, MD, Erasmus MC University Medical Center Rotterdam, The Netherlands, Department of Gastroenterology and Hepatology, Postbus 2040, 3000 CA Rotterdam, The Netherlands

Fax: +0031107030331

s.e.vanderwiel@erasmusmc.nl

\section{ABSTRACT}

Background and study aims Simulation-based training has become an important pillar in competence-based medicine. However, limited data are available on use of simulators in training for endoscopic retrograde cholangiopancreatography (ERCP). We aimed to determine the face and construct validity of the Boškoski-Costamagna mechanical
ERCP Trainer, and to assess its didactic value, as judged by experts.

Methods Participants were divided into four groups based on ERCP lifetime experience: novices, intermediate, experienced, and experts. Participants performed several standardized assignments on the simulator. Outcome parameters included times to complete the procedure, ability to cannulate both ducts, number of attempts to cannulate the common bile duct and pancreatic duct, number of inadvertent pancreatic duct cannulations, successful stent placement, and successful stone extraction. All experts filled out a questionnaire on the simulator's realism and didactic value.

Results Novices $(n=11)$ completed the total procedure in $21: 09$ (min:sec), intermediates $(n=5)$ in 10:58, experienced $(n=8)$ in 06:42 and experts $(n=22)$ in 06:05. Experts were significantly faster than novices (Kruskal-Wallis test $P<$ 0.000 ). Experts rated the realism of the simulator 7.12 on a 10-point Likert scale. The simulator's potential as a tool for training novices was rated 3.91 on a four-point Likert scale, and there was a high agreement among experts to include the simulator in the training of novice endoscopists (3.86 on a four-point Likert scale).

Conclusions The novel Boškoski-Costamagna ERCP simulator demonstrates good face and construct validity. ERCP experts highly agree on the didactic value and added value of this simulator in the training curriculum for novice endoscopists.

\section{Introduction}

ERCP is considered to be an advanced endoscopic procedure and is one of the most technically demanding and high-risk procedures in gastrointestinal endoscopy. The procedure may result in life-threatening short-term and long-term complications, and therefore, ERCP carries a higher risk for morbidity and mortality than most other endoscopic procedures [1]. Achieving competence in ERCP requires a great deal of training and an extensive number of procedures, but there is still no consensus on assessment of a trainee's competence. Currently, in most training centers around the world, threshold numbers are still used as a surrogate for competency and certification. The first publications concerning the minimal number of ERCP procedures that must have been completed to gain technical competence were published back in the early $1990 \mathrm{~s}$ and report numbers ranging from 100 to 180 procedures [2-4]. The current guideline of the American Society for Gastrointestinal Endoscopy (ASGE) recommends mastery of at least 200 ERCP procedures to gain competence [5]. However, a recent study by Cotton et al. describes that only a minimal number of hospitals in the United States adhere to these guidelines [6]. Thereby, there is growing evidence that competence should be established by objective performance criteria [7-9]. 
Nowadays, trainees learn to perform ERCP with hands-on training in a clinical setting on real patients under the supervision of a trained endoscopist: the so-called master apprentice model. This setting offers immediate feedback from an experienced endoscopist, but it also has certain drawbacks. Trainees learn by "trial and error," which potentially increases patient discomfort and risk of complications and prolongs procedure time, which has additional economic consequences. Simulators offer the potential to train in a dedicated 'learning environment, offering a less stressful situation with less potential risks and the opportunity to endlessly repeat specific tasks.

Simulator-based gastrointestinal endoscopy training has gained acceptance over recent decades and has been extensively studied. Multiple simulators have been validated and it has been demonstrated that use of simulators in gastrointestinal endoscopy accelerates the early learning curve of trainees [10 - 13]. The proven value of simulator-based training has led to the recommendation tp introduce gastrointestinal simulators in the curriculum for endoscopists being trained in forward-viewing endoscopy [12]. Simulator-based training seems ideally suited as a training platform for ERCP, due to the complexity of this procedure and its associated complications. Although simulator training in ERCP has been possible for quite some time now, there are very limited scientific data on application of endoscopic simulators in ERCP in training novice endoscopists. Six simulators have been described in the literature. Nevertheless, despite their definite training potential, the applicability of each of the simulators as a certified training tool has not been demonstrated. Before using a novel simulator as a training tool, it is essential to carry out a study to scientifically determine its validity. Studies evaluating face and construct validity demonstrate the appropriateness of using a simulator for training or assessment $[14,15]$. Validity assessment of a medical simulator can be performed on different levels. One of the most commonly used forms of validation is face validity, in which a defined group of subjects are asked to judge the degree of resemblance between a training simulator and the real activity. This is often combined with construct validity. This describes the degree to which the assessment can discriminate between different experience levels. The most powerful evidence is gained through concurrent validity, in which performance on the system is compared with outcomes from an established assessment method designed to measure the same skills or attributes. This implies that experience gained by training on the simulator results in improved performance in patient-based procedures [13-15].

The Boŝkoski-Costamagna ERCP Trainer is a novel mechanical ERCP training model developed and produced by Cook Medical (Cook Medical, Limerick, Ireland) in close collaboration with the Digestive Endoscopy Unit of the Gemelli Hospital in Rome, Italy (Dr. Boŝkoski and Prof. Dr. Costamagna). It is designed to guide trainees on how to correctly position the endoscope in front of the papilla in order to attain a proper axis and to achieve deep cannulation from where several therapeutic interventions can be performed, such as plastic or metal stent placement and stone extraction [16]. An initial report has been published by Jovanovic et all showing the potential value of the model [17]. However, no attempt was made to scientifically assess the validity of the model. The current study had three aims: to determine whether the simulator can distinguish between endoscopists with different levels of experience (construct validity); to evaluate the extent to which the ERCP simulator simulates actual ERCP procedures (face validity); and to assess the value of the simulator as a training tool, as judged by experts.

\section{Methods}

\section{Simulator}

The Boškoski-Costamagna ERCP Trainer (Cook Medical, Limerick, Ireland) is a mechanical endoscopic simulator ( $>$ Fig. 1 and

- Fig. 2). The simulator has been designed to train residents on correct positioning of the endoscope, based on the knowledge that a successful ERCP procedure is largely dependent upon the ability to achieve an optimal position of the scope tip in front of the papilla. The model consists of a metal framework with the esophagus, stomach, and duodenum constructed from plastic. The various papillae are made out of latex with both bile and pancreatic ducts inserted in different varieties intended to resemble known anatomical variations. The simulator enables use of a real endoscope and commonly used equipment. The model can be placed on a table and real-time fluoroscopy image is made visible on a secondary screen using a small camera ( Fig.3). The Boškoski-Costamagna ERCP Trainer can simulate different patient positions (prone, oblique and supine) and a variety of ERCP procedures: scope insertion, wheel and elevator handling, selectively cannulating the bile and pancreatic duct, stone extraction, and both metal and plastic stent insertion. The level of difficulty can be adjusted based on variations of the papillary anatomy and biliopancreatic junction [16]. The version using during this entire study was the second generation of the ERCP Trainer.

\section{Participants}

We included four groups of participants in this study: novices, intermediates, experienced, and experts. The participants were divided into these groups based on lifetime ERCP experience. There is no consensus in the literature when it comes to numbers expressing experience levels in ERCP. Therefore, we attempted to define the groups according to the largest reported numbers in the literature [18-20]. The bar for the expert group was deliberately raised to 2500 ERCPs lifetime to reassure an expert group with an undisputed reputation. The first group, the novices, was defined as participants with less than 50 lifetime ERCPs. The second group, the intermediates, had a lifetime experience of 50 to 600 ERCPs. The third group consisted of experienced participants with a lifetime experience of 601 to 2500 ERCPs. Based on previous studies concerning ERCP, we assumed that experts would be twice as fast at completing the ERCP simulator assignments compared to novices $[19,21,22]$. A sample size calculation reveals a minimal sample of seven participants both in the novice and expert groups to achieve a power of 0.80 . 


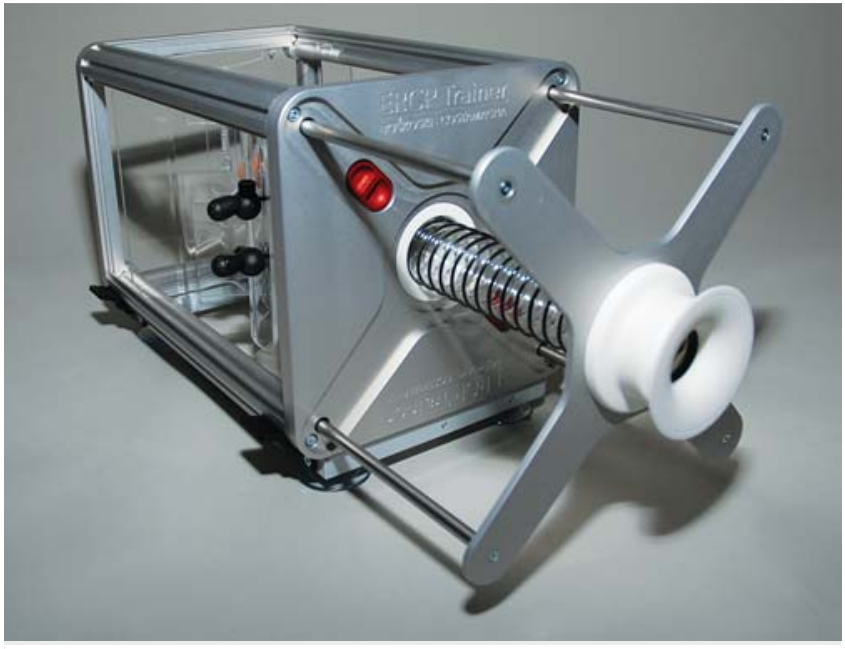

Fig. 1 The Boŝkoski-Costamagna ERCP Trainer.

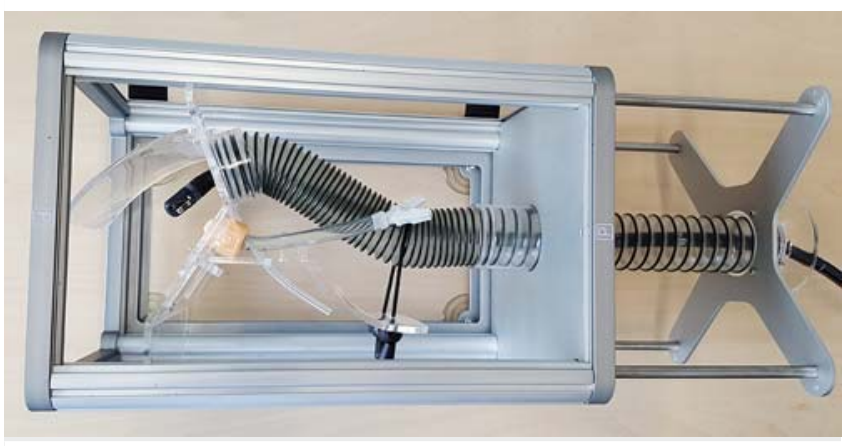

Fig. 2 The Boŝkoski-Costamagna ERCP Trainer: perspective from above.

All participants were invited for a simulator session in a similar private conference room either in our hospital, during a national conference of the Dutch Society of Gastroenterology in spring 2016 or during Digestive Disease Week in May 2016. During the procedures the participants were assisted by five alternating endoscopy nurses from the Erasmus MC with broad experience in assisting ERCP procedures and good English conversation skills.

\section{Questionnaire}

All participants filled out a questionnaire on demographics, medical experience, and endoscopy experience. Endoscopy experience included the number of various endoscopic procedures performed annually and estimated lifetime numbers. In addition, participants were asked about previous experience with other medical simulators. After performing a standardized set of assignments on the simulator, experts were asked to rate their appreciation of the realism of the ERCP Trainer. Appreciation was expressed on a 10-point Likert scale [23], varying from very unrealistic (1) to very realistic (10). Questions were asked about the realism of the simulator setup, anatomical representation, difficulty, handling of the endoscope, haptic feedback, and imaging. In addition, experts were asked to evaluate the di-

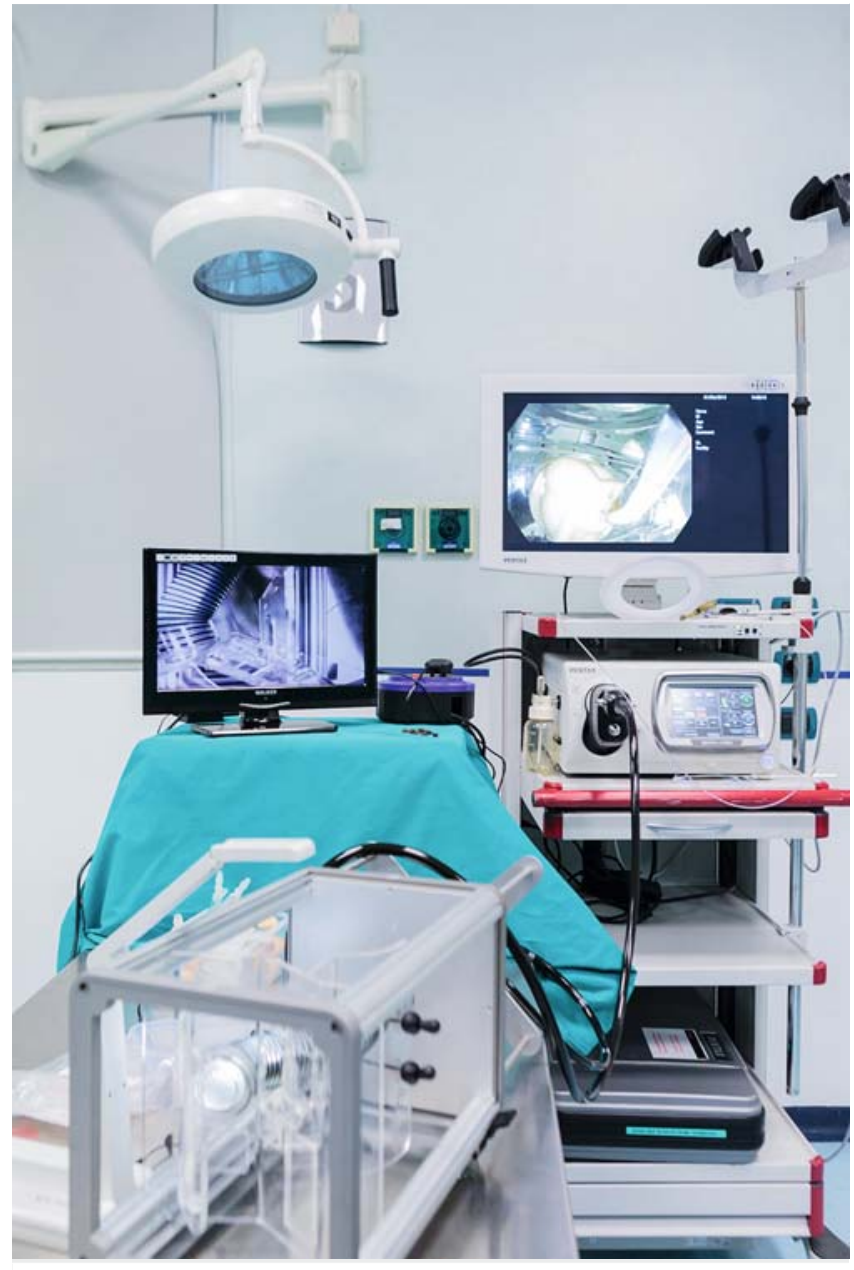

- Fig. 3 Complete simulator set-up.

dactic value of the Boškoski-Costamagna ERCP Trainer on a four-point Likert Scale.

\section{ERCP simulation}

All participants were invited to perform six standardized assignments. The first assignment was to establish the correct position of the endoscope in front of the papilla to gain a proper axis for cannulation. The second assignment was to cannulate the common bile duct (CBD) during which the number of unintentional pancreatic duct (PD) cannulations was also scored. The same applied for PD cannulation and unintentional CBD cannulations. Next, participants were asked to place a plastic stent in the PD and a plastic stent in the CBD. Finally, participants were asked to extract a single stone from the CBD using an extraction basket. A coffee bean was used as a stone. For each exercise, time was recorded, with a time limit of 10 minutes per assignment for logistical reasons. After 10 minutes the procedure was scored as failed. Participants were not made aware of the time limit at the start of the assignment and they were encouraged to complete the exercises to best of their ability without a competitive intent. 


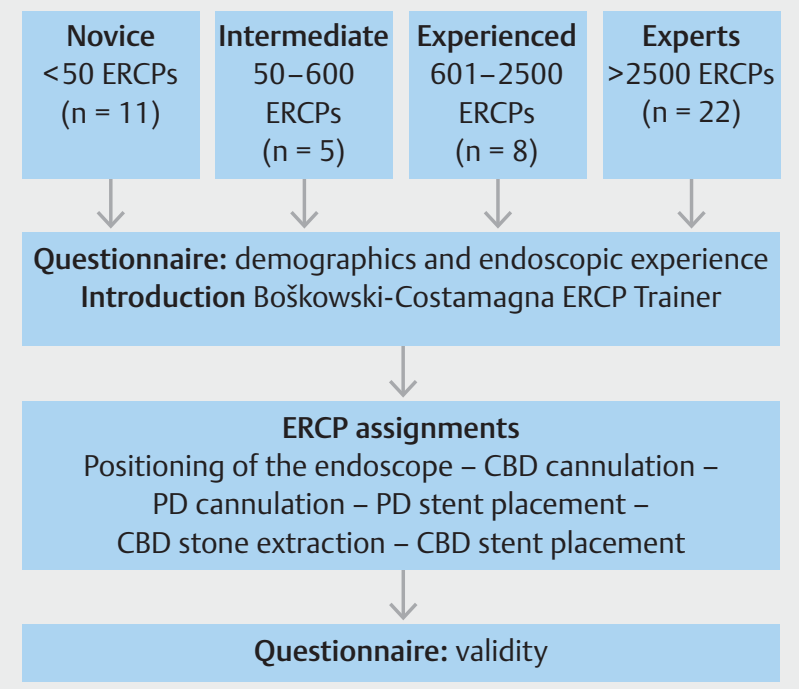

$\checkmark$ Fig. 4 Study design.

\section{Data analysis}

All statistical analyses were performed using SPSS 21.0 software (IBM Corp: Armonk, NY). Descriptive statistics were used for all measures. Assuming that the experts required less time to fulfil the assignments compared to novices, variations in outcomes between groups were compared using a Kruskal-Wallis test. A separate analysis between the four groups was performed using a Mann-Whitney $U$ Test. Data are presented as median and range. A $P$ value $<0.05$ was considered significant.

\section{Results}

\section{Participants}

In total, 46 participants were included in the study, 11 novices, 5 intermediates, 8 experienced ERCPists and 22 ERCP experts, they originated from 20 different countries from all continents. The percentage of female participants was $21.7 \%$ and all ERCP experts were male. The mean number of years of endoscopic experience was 23.32 (range 15-34) for experts and 1.6 years for novices (range $0.1-5.0$ ). Novices claimed $100 \%$ familiarity with previous use of endoscopy simulators, experts reported $77.3 \%$. All participants completed the exercises and filled out the evaluation form. $\$$ Fig. 4 shows the study design and baseline characteristics can be found in $>$ Table 1 .

\section{Face validity}

The ERCP experts rated the Boŝkoski-Costamagna ERCP Trainer 7.12 on a 10-point Likert scale for overall realism. $>$ Table 2 details the experts' average ratings of various components of the simulator. - Table 3 demonstrates the perceived opinion of the ERCP-specific components, as judged by experts. In general, most of the experts rated the more complex procedural aspects of the Boŝkoski-Costamagna ERCP Trainer as very realistic. Biliary plastic stent placement scored 7.99 on a 10-point Likert scale, pancreatic plastic stent placement 7.80 and removal of a common bile duct stone 7.42 .

\section{Construct validity}

Construct validity of the Boŝkoski-Costamagna ERCP Trainer was evaluated by comparing the procedure time and attempts at success per assignment across the four groups. Data output regarding the construct validity is presented in $>$ Table 4 and - Table5. All assignments were completed faster by the experts $(P=0.000)$, experienced $(P=0.000)$ and intermediate $(P=$ 0.052 ) than by the novices ( $\triangleright$ Table 3$)$. Novices $(n=11)$ completed the procedure in a mean time of 21.09 (min:sec), intermediates $(n=5)$ in 10.58 , experienced $(n=8)$ in 06.42, and experts $(n=22)$ in 06.05. Unintentional CBD cannulation occurred with a median of 4.6 in novices, 0.8 for intermediates, 2.0 for experienced, and 1.4 unintended CBD cannulations for experts $(P=0.028)$. Unintended PD cannulation occurred less frequently, median of 0.4 for novices, 0 unintended cannulations for intermediates and experienced, and 0.2 for experts $(P=0.449)$. There were no statistical differences between novices and experts in the number of attempts per assignment $(P=0.985)$. We performed a separate analysis between the four groups using a Mann-Whitney $U$ test. No statistical significant differences were seen between the intermediate, experienced and ex-

\section{- Table 1 Baseline characteristics.}

\begin{tabular}{|c|c|c|c|c|c|}
\hline & Novices & Intermediate & Experienced & Experts & Total \\
\hline No. participants & 11 & 5 & 8 & 22 & 46 \\
\hline Male (\%) & 27.3 & 60 & 100 & 100 & 78.3 \\
\hline Mean age $(y)$ & 32.3 & 38.4 & 46.5 & 52.0 & 45.0 \\
\hline Academic hospital (\%) & 45.5 & 100 & 87.5 & 95.5 & 82.6 \\
\hline Endoscopic experience (y) & 1.63 & 7.2 & 15.5 & 23.3 & 15.1 \\
\hline Simulator familiarity (\%) & 100 & 80 & 62.5 & 77.3 & 80.4 \\
\hline
\end{tabular}

Novice, 10 fellows and 1 gastroenterologist; intermediate, 3 gastroenterologists, 1 fellow and 1 surgeon; experienced, 7 gastroenterologists and 1 surgeon; experts, 20 gastroenterologists and 2 surgeons. 
- Table 2 Expert opinion on the Boŝkoski-Costamagna ERCP Trainer.

\begin{tabular}{|l|l|}
\hline Component & $\begin{array}{l}\text { Average rating' } \\
\mathbf{n = 2 2}\end{array}$ \\
\hline Overall realism & 7.12 \\
\hline Overall difficulty & 6.86 \\
\hline Simulator setup & 7.50 \\
\hline Anatomical representation & 7.18 \\
\hline Endoscopic control & 7.70 \\
\hline Haptic feedback & 7.32 \\
\hline Endoscopic image presentation & 7.82 \\
\hline Radiologic image presentation & 6.41 \\
\hline $\begin{array}{l}\text { 1 Scores are based on a 10-point Likert Scale (1=very unrealistic, 10=very } \\
\text { realistic) }\end{array}$ \\
\hline
\end{tabular}

perts, all of whom performed all assignments faster than the novices ( $\triangleright$ Table 4 ).

\section{Didactic/training value}

Expert opinion was that the Boŝkoski-Costamagna ERCP Trainer is a useful tool in the basic training of a novice endoscopist (3.91 on a 4-point Likert scale) and that the ERCP trainer should be incorporated into the training of novice endoscopists (3.86 on a 4-point scale). The expertise gained on this simulator should be applicable in a clinical curriculum (3.59 on a 4-point scale). Most experts agreed that there is a limited role for the simulator in training of experienced ERCP-performing endoscopists (rated 1.86 on a 4-point scale).

\section{Discussion}

This study reports the first formal validation of the BoškoskiCostamagna mechanical ERCP Trainer and demonstrates good construct and face validity. We demonstrated results of endoscopists who originated from all over the world, classified in four different expertise levels based on ERCP lifetime experience. The data reveal that the simulator is able to discriminate between different levels of expertise. Both experienced and expert endoscopists demonstrated superior performance, compared to novices, on all parts of the ERCP procedure.

All experts agree that the Boškoski-Costamagna ERCP Trainer seems to offer a satisfactory representation of clinical ERCP and that the expertise gained on the simulator should be transferrable to a clinical curriculum. Tactile feedback from the simulator was evaluated positively, even though the mechanical ERCP simulator is constructed from plastic and rubber components. The specific strengths of the simulator are the high levels of realism of more complex ERCP interventions, such as stent placement and stone extraction. This means that this novel ERCP simulator provides a platform with which to train inexperienced endoscopists in these complex procedures until they feel comfortable and perform up to a certain standard before exposing them to actual patient procedures. Our data do not
Table 3 Expert opinion on the Boŝkoski-Costamagna ERCP TrainerERCP procedures.

\begin{tabular}{|c|c|c|}
\hline Component & & $\begin{array}{l}\text { Average } \\
\text { rating }{ }^{1} \\
n=22\end{array}$ \\
\hline \multirow{4}{*}{$\begin{array}{l}\text { Biliary plastic stent } \\
\text { placement }\end{array}$} & Overall & 7.99 \\
\hline & Anatomical representation & 8.23 \\
\hline & Endoscopic control & 8.24 \\
\hline & Haptic feedback & 7.64 \\
\hline \multirow{4}{*}{$\begin{array}{l}\text { Pancreatic plastic } \\
\text { stent placement }\end{array}$} & Overall & 7.80 \\
\hline & Anatomical representation & 7.90 \\
\hline & Endoscopic control & 8.10 \\
\hline & Haptic feedback & 7.52 \\
\hline \multirow[t]{4}{*}{ Stone removal } & Overall & 7.42 \\
\hline & Anatomical representation & 7.59 \\
\hline & Endoscopic control & 7.64 \\
\hline & Haptic feedback & 7.05 \\
\hline \multicolumn{3}{|c|}{$\begin{array}{l}\text { ERCP, endoscopic retrograde cholangiopancreatography } \\
1 \text { Scores are based on a } 10 \text {-point Likert Scale ( } 1=\text { very unrealistic, } 10=\text { very } \\
\text { realistic) }\end{array}$} \\
\hline
\end{tabular}

support the use of this simulator in training endoscopists who already have a more experienced performance level.

A recent systematic review by our study group [10] presented an overview of currently available simulators and their known potential in training novices. Only six simulators have previously been described in the literature [18, 19, 21, 24-26]. A comparison validation study of three of the available simulators was performed by Sedlack et al. [27]. They included the Erlangen Endo Trainer, a bio simulation model, the live porcine model and the GI Mentor II, a virtual reality simulator. The study describes the potential value of all the simulators in training novice endoscopists, but they all have certain advantages and disadvantages. In terms of realism, bio-simulation models and live porcine models scored higher than mechanical and virtual reality simulators. However, major drawbacks of these types of simulators include costs and organizational difficulties due to the ethical incidentals. The X-Vision ERCP training simulator and the ERCP mechanical simulator have not been included in the study by Sedlack et al., both mechanical simulators [21,22]. The X-vision ERCP trainer has been validated, but no studies have been published on implementation of the model in a training setting. The ERCP Mechanical Simulator has proven its training value in novice trainees [28].

There were some limitations in our study. It would have been ideal to include only naive trainees in the group with novices, whereas we included five novices without any experience and six novices who had performed fewer than 50 ERCPs. There is bias in terms of exposure and experience. However, with the 
- Table4 ERCP assignments overview in procedural time.

\begin{tabular}{|c|c|c|c|c|c|c|}
\hline & & $\begin{array}{l}\text { Novice } \\
\mathrm{n}=\mathbf{1 1}\end{array}$ & $\begin{array}{l}\text { Intermediate } \\
\mathrm{n}=\mathbf{5}\end{array}$ & $\begin{array}{l}\text { Experienced } \\
\mathrm{n}=\mathbf{8}\end{array}$ & $\begin{array}{l}\text { Expert } \\
n=22\end{array}$ & $P$ value $^{1}$ \\
\hline \multirow[t]{3}{*}{ Positioning endoscope } & Mean & 01:07 & $00: 26$ & $00: 11$ & $00: 14$ & \multirow[t]{3}{*}{0.000} \\
\hline & Median & 00:59 & $00: 15$ & $00: 10$ & $00: 12$ & \\
\hline & Range & $00: 25-02: 31$ & $00: 09-01: 08$ & $00: 08-00: 20$ & $00: 06-00: 40$ & \\
\hline \multirow[t]{3}{*}{ CBD cannulation } & Mean & 02:03 & $01: 36$ & $00: 48$ & 00:39 & \multirow[t]{3}{*}{0.000} \\
\hline & Median & 02:05 & $00: 52$ & $00: 45$ & $00: 40$ & \\
\hline & Range & $00: 37-04: 05$ & $00: 28-03: 24$ & $00: 11-01: 14$ & $00: 05-01: 31$ & \\
\hline \multirow[t]{3}{*}{ PD cannulation } & Mean & $05: 47$ & $01: 55$ & 01:09 & 01:06 & \multirow[t]{3}{*}{0.013} \\
\hline & Median & $06: 27$ & $01: 17$ & $01: 13$ & $00: 27$ & \\
\hline & Range & $00: 12-10: 00$ & $00: 13-06: 18$ & $00: 05-03: 58$ & $00: 06-05: 17$ & \\
\hline \multirow[t]{3}{*}{ PD stent placement } & Mean & 03:35 & $00: 43$ & $00: 45$ & 00:39 & \multirow[t]{3}{*}{0.000} \\
\hline & Median & $06: 53$ & $00: 47$ & $00: 48$ & $00: 38$ & \\
\hline & Range & $01: 15-10: 00$ & $00: 30-00: 49$ & $00: 26-01: 12$ & $00: 13-01: 27$ & \\
\hline \multirow[t]{3}{*}{ CBD stone extraction } & Mean & 05:11 & 03:05 & 02:31 & $01: 25$ & \multirow[t]{3}{*}{0.044} \\
\hline & Median & 03:55 & 01:46 & $02: 41$ & 01:06 & \\
\hline & Range & $01: 38-10: 00$ & $00: 47-10: 00$ & $00: 32-04: 24$ & $00: 37-03: 32$ & \\
\hline \multirow[t]{3}{*}{ CBD stent placement } & Mean & $04: 21$ & 03:11 & $01: 15$ & $01: 25$ & \multirow[t]{3}{*}{0.000} \\
\hline & Median & 03:42 & 01:56 & 01:08 & 01:06 & \\
\hline & Range & $01: 14-10: 00$ & $01: 03-08: 38$ & $00: 51-01: 48$ & $00: 37-03: 32$ & \\
\hline \multirow[t]{3}{*}{ Total procedure time } & Mean & 21:09 & $10: 58$ & $06: 42$ & 06:05 & \multirow[t]{3}{*}{0.000} \\
\hline & Median & $20: 21$ & $10: 20$ & $06: 33$ & 05:39 & \\
\hline & Range & $07: 16-34: 07$ & $04: 20-28: 49$ & $04: 32-09: 10$ & $02: 32-12: 02$ & \\
\hline \multicolumn{7}{|c|}{$\begin{array}{l}\text { Procedural time in mm:ss } \\
\text { CBD, common bile duct; PD, pancreatic duct } \\
1 \text { Kruskal-Wallis Test }\end{array}$} \\
\hline
\end{tabular}

current ASGE guidelines in mind, defining ERCP competence after at least 200 cases [5], our novices are all in their very early learning curve. Another limitation might be use of procedure times for the various ERCP assignments as a proxy for competence. Time as a surrogate marker for outcome is not ideal. However, in many simulation validation studies, use of procedure times is unavoidable. This is an accepted method where participants are not made aware of the time element and encouraged not to give their fastest but to give their best performance [21, 29-32].

We believe that, compared to the previously described simulators, the Boškoski-Costamagna ERCP Trainer has added value. It has the advantage that a real endoscope and real accessories are used, providing novice endoscopists with the opportunity to learn how to handle the movements of the endoscope and experience the haptic feedback of their actions. A fluoroscopic image is created with the use of a simple camera, without the need for specific $x$-ray equipment. The total set-up creates the feel of a standard endoscopy unit. The Boškoski-Costamagna ERCP Trainer is light enough to be transported and easy to set up, and its use is not restricted to a specific environment. Despite the mechanical aspect of the model, its realism was scored satisfactory by experts. Experts believe that the Boškoski-Costamagna ERCP Trainer will improve trainee performance in the early training setting.

\section{Conclusion}

The Boškoski-Costamagna ERCP Trainer demonstrates good face and construct validity as a novel simulator for basic ERCP training. Experts generally agree on the didactic strength and added value of this simulator in the training curriculum for novice endoscopists.

\section{Acknowledgements}

This study was funded by an unrestricted grant for investigatorinitiated research by Cook Medical, Limerick, Ireland. 
- Table 5 Differences between groups.

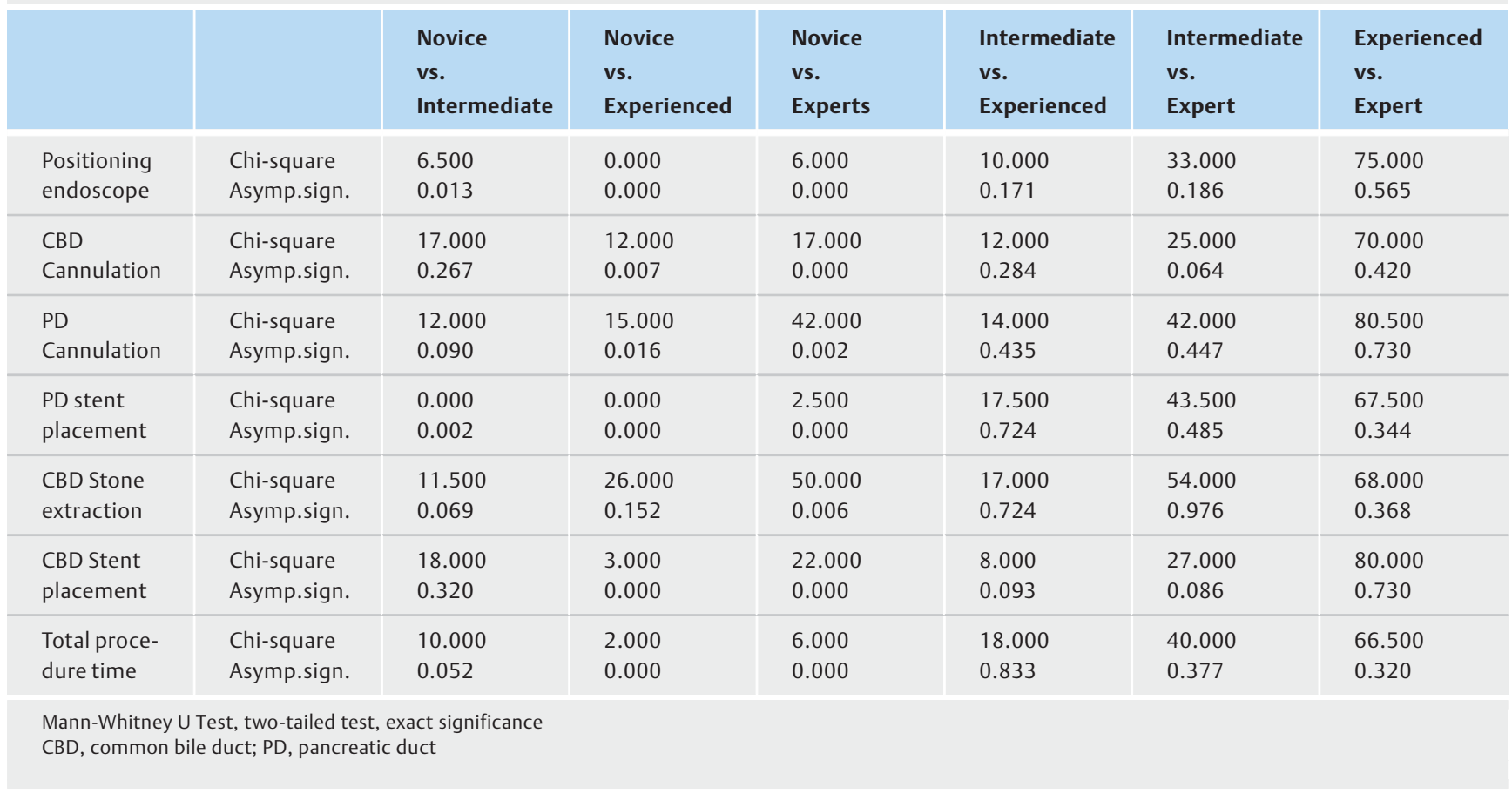

\section{Participants}

Ang Tiing Leong, MD, PhD

Antonie J. P. van Tilburg, MD, PhD

Arjun D. Koch, MD, PhD

Bart Opsteeg, MD

Benedict Devereaux, MD, PhD

David F. Boerwinkel, MD, PhD

Dorien J. Buurman, MD, PhD

Dorien Oude Hergelink, MD, PhD

Ernst J. Kuipers, MD, PhD

Fauze Maluf- Filho, MD, PhD

Femme Harinck, MD, PhD

Fernando Marson, MD, PhD

Francisco M. Tufare, MD, PhD

Frank Ter Borg, MD, PhD

Fred M. Konikoff, MD, PhD

George J. Websterm, MD, PhD

Hrvoje Iveković, MD, PhD

Hugo Richter Roca, MD, PhD

Inge van Rongen, MD, PhD

Jesús Rodriguez, MD, PhD

Jorge Cerecedo, MD, PhD

Judith E. Baars, MD, PhD

Lars Aabakken, MD, PhD

Lars Enochsson, MD, PhD

Lieke Hol, MD, PhD

Marc Giovannini, MD, PhD

Marjan R. S. Drenth, MD

Martin Goetz, MD, PhD

Martin W. James, MD, PhD

Matthijs P. Schwartz, MD, PhD
Michael L. Kochman, MD, PhD

Milutin Bulajic, MD, PhD

Moniek H. P. Gorter, MD

Paola Figueroa-Barojas, MD, PhD

Paul Didden, MD

Pietro Familiari, MD, PhD

Rastislav Kunda, MD, PhD

Raul F. Matano, MD, PhD

Renato Baracat, MD, PhD

Sarah N. Mutsaers, MD

Stefan Seewald, MD, PhD

Takai Itoi, MD, PhD

Thierry Ponchon, MD, PhD

Todd H. Baron, MD, PhD

Wout O. A. Rohof, MD, PhD

Competing interests

Dr. van der Wiel has nothing to disclose. Dr. Bruno reports institutional study support by unrestricted grant from Cook Medical, Consultancy and lecturer Fees from Boston Scientific and Cook Medical. Dr. Koch reports Consultancy and lecturer Fee from Cook Medical.

\section{References}

[1] Andriulli A, Loperfido S, Napolitano G et al. Incidence rates of postERCP complications: a systematic survey of prospective studies. Am J Gastroenterol 2007; 102: 1781-1788 
[2] Watkins JL, Etzkorn KP, Wiley TE et al. Assessment of technical competence during ERCP training. Gastrointest Endosc 1996; 44: 411 415

[3] Jowell PS, Baillie J, Branch MS et al. Quantitative assessment of procedural competence. A prospective study of training in endoscopic retrograde cholangiopancreatography. Ann Intern Med 1996; 125 : $983-989$

[4] Ekkelenkamp VE, Koch AD, Rauws EA et al. Competence development in ERCP: the learning curve of novice trainees. Endoscopy 2014; 46: 949-955

[5] Committee AT, Jorgensen J, Kubiliun $\mathrm{N}$ et al. Endoscopic retrograde cholangiopancreatography (ERCP): core curriculum. Gastrointest Endosc 2016; 83: 279-289

[6] Cotton PB, Feussner D, Dufault D et al. A survey of credentialing for ERCP in the United States. Gastrointest Endosc 2017; 86: 866- 869

[7] Baron TH, Petersen BT, Mergener K et al. Quality indicators for endoscopic retrograde cholangiopancreatography. Gastrointest Endosc 2006; 63: S29- 34

[8] Chutkan RK, Ahmad AS, Cohen J et al. ERCP core curriculum. Gastrointest Endosc 2006; 63: 361 - 376

[9] Neerlandicum CG. Herstructurering Opleiding Maag-Darm-Leverziekten. 2008

[10] van der Wiel SE, Kuttner Magalhaes R, Rocha GoncalvesCR et al. Simulator training in gastrointestinal endoscopy - From basic training to advanced endoscopic procedures. Best Pract Res Clin Gastroenterol 2016; 30: $375-387$

[11] Lim BS, Leung JW, Lee J et al. Effect of ERCP mechanical simulator (EMS) practice on trainees' ERCP performance in the early learning period: US multicenter randomized controlled trial. Am J Gastroenterol 2011; 106: $300-306$

[12] Ekkelenkamp VE, Koch AD, de Man RA et al. Training and competence assessment in $\mathrm{Gl}$ endoscopy: a systematic review. Gut 2016; 65: 607 615

[13] Koch AD, Ekkelenkamp VE, Haringsma J et al. Simulated colonoscopy training leads to improved performance during patient-based assessment. Gastrointest Endosc 2015; 81: 630-636

[14] Carter FJ, Schijven MP, Aggarwal R et al. Consensus guidelines for validation of virtual reality surgical simulators. Simul Healthc 2006; 1: $171-179$

[15] Allerton DJ. Principles of Flight Simulation Wiley. 2009

[16] Boskoski I, Costamagna G. The Boskoski-Costamagna ERCP Trainer: from dream to reality. Endoscopy 2016; 48: 593
[17] Jovanovic I, Fry LC, Rustemovic N et al. Initial validation of a simple, nonbiological, mechanical ERCP training model for cannulation and stent placement. Endoscopy 2015; 47: (Suppl. 01): E585 - 586

[18] Sahakian AB, Laine L, Jamidar PA et al. Can a computerized simulator assess skill level and improvement in performance of ERCP? Dig Dis Sci 2016; 61: $722-730$

[19] Bittner JGt, Mellinger JD, Imam T et al. Face and construct validity of a computer-based virtual reality simulator for ERCP. Gastrointest Endosc 2010; 71: $357-364$

[20] Arnold SH, Svendsen MB, Konge L et al. Three-dimensional motion tracking correlates with skill level in upper gastrointestinal endoscopy. Endoscopy 2015; 47: 825-828

[21] Leung JW, Lee JG, Rojany M et al. Development of a novel ERCP mechanical simulator. Gastrointest Endosc 2007; 65: 1056 - 1062

[22] von Delius S, Thies P, Meining A et al. Validation of the X-Vision ERCP Training System and technical challenges during early training of sphincterotomy. Clin Gastroenterol Hepatol 2009; 7: 389-396

[23] Lickert R. A Technique for the Measurement of Attitudes. Arch Psychol 1932; 140: 5 - 55

[24] Frimberger E, von Delius S, Rosch T et al. A novel and practicable ERCP training system with simulated fluoroscopy. Endoscopy 2008; 40: $517-520$

[25] Neumann M, Mayer G, Ell C et al. The Erlangen Endo-Trainer: life-like simulation for diagnostic and interventional endoscopic retrograde cholangiography. Endoscopy 2000; 32: $906-910$

[26] Sedlack RE, Petersen BT, Kolars JC. The impact of a hands-on ERCP workshop on clinical practice. Gastrointest Endosc 2005; 61: 67-71

[27] Sedlack R, Petersen B, Binmoeller K et al. A direct comparison of ERCP teaching models. Gastrointest Endosc 2003; 57: 886-890

[28] Liao WC, Leung JW, Wang HP et al. Coached practice using ERCP mechanical simulator improves trainees' ERCP performance: a randomized controlled trial. Endoscopy 2013; 45: 799-805

[29] Sedlack RE, Baron TH, Downing SM et al. Validation of a colonoscopy simulation model for skills assessment. Am J Gastroenterol 2007; 102: $64-74$

[30] Fayez R, Feldman LS, Kaneva P et al. Testing the construct validity of the Simbionix GI Mentor II virtual reality colonoscopy simulator metrics: module matters. Surg Endosc 2010; 24: 1060 - 1065

[31] Haycock AV, Bassett P, Bladen J et al. Validation of the second-generation Olympus colonoscopy simulator for skills assessment. Endoscopy 2009; 41: $952-958$

[32] Koch AD, Buzink SN, Heemskerk J et al. Expert and construct validity of the Simbionix GI Mentor II endoscopy simulator for colonoscopy. Surg Endosc 2008; 22: 158 - 162 